\title{
Recomendaciones sobre Difusión de Cloruros
}

\section{Recomendaciones Técnicas}

\section{Miguel-Ángel Climent André Tavares da Cunha Guimarães Valentina Millano}

https://doi.org/10.21041/AlconpatInternacional/RecTec/2020-07-difusiondecloruros

\section{ALCONPAT Internacional}

Asociación Latinoamericana de Control de Calidad, Patología y Recuperación de la Construcción

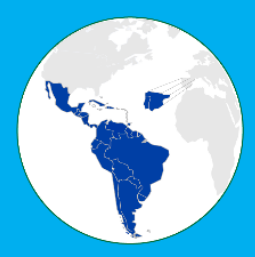




\section{$\mathrm{R}_{\text {ECOMENDACIÓN }} \mathrm{T}_{\text {ÉCNICA }}$}

\section{Editores}

Pedro Garcés Terradillos

Director de Recomendaciones Técnicas

Universidad de Alicante, España
Jorge Alberto Briceño Mena

Subdirector de Recomendaciones Técnicas

Cinvestav del IPN, Unidad Mérida, México

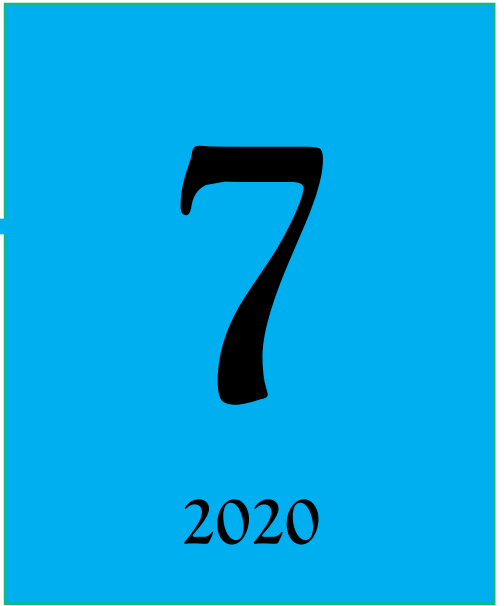

Recomendaciones sobre difusión de cloruros

DOI: https://doi.org/10.21041/AlconpatInternacional/RecTec/2020-07difusiondecloruros

Recomendações sobre difusão de cloretos

\section{Recommendations on chloride diffusion}

\section{Miguel-Ángel Climent}

Universidad de Alicante, Alicante, España.

\section{André Tavares da Cunha Guimarães}

Universidade Federal do Rio Grande,

Rio Grande do Sul, Brasil.

\section{Valentina Millano}

Universidad del Zulia,

Maracaibo, Venezuela 


\section{Recomendación Técnica No. 7}

\section{DETERMINACIÓN DE LA RESISTENCIA DEL CONCRETO A LA PENETRACIÓN DE IONES CLORURO, DIFUSIÓN UNIDIRECCIONAL EN ESTADO NO ESTACIONARIO}

\section{OBJETIVO}

Esta Recomendación Técnica tiene por objeto describir un método para la determinación de diferentes parámetros relacionados con la penetración unidireccional de cloruro, en condiciones de estado no estacionario, en probetas de concreto endurecido.

\section{INTRODUCCIÓN}

Las estructuras de concreto reforzado o pretensado expuestas al ingreso de iones cloruro $\left(\mathrm{Cl}^{-}\right)$, procedentes del agua de mar o de otras fuentes, necesitan ser durables durante al menos su periodo previsto de vida útil. La posibilidad de que se vean afectadas por corrosión de las armaduras se incrementa significativamente cuando el contenido de $\mathrm{Cl}^{-}$ aumenta en la zona en contacto con el acero embebido. Uno de los mecanismos principales de transporte de $\mathrm{Cl}^{-}$en el concreto es el de difusión. Por esta razón la difusividad del ion $\mathrm{Cl}^{-}$a través del concreto se considera una propiedad importante que representa la penetrabilidad del concreto a dicho ion. La presente Recomendación Técnica establece un método que puede ser aplicado a probetas de hormigón moldeadas con el objetivo de estimar la resistencia potencial de una mezcla de concreto a la penetración del cloruro.

\section{ALCANCE}

La presente Recomendación Técnica describe un método para la determinación de diferentes parámetros relacionados con la penetración unidireccional de cloruro, en condiciones de estado no estacionario, en probetas de concreto endurecido. El procedimiento permite determinar el coeficiente de difusión del ión $\mathrm{Cl}^{-}$a una edad determinada, por ejemplo, con la finalidad de comparar experimentalmente las propiedades de diferentes mezclas de concreto. Debe tenerse en cuenta que la resistencia a la penetración de cloruro cambia con la edad del concreto, debido a efectos de modificación de la microestructura del material por hidratación del cemento $\mathrm{o}$ materiales cementantes suplementarios. Por ello las comparaciones mencionadas anteriormente pueden modificarse con la edad del concreto.

El procedimiento propuesto no es aplicable a concretos tratados con productos hidrofugantes, y podría no ser aplicable a concretos conteniendo fibras.

Existen diferentes normas dedicadas a la descripción de procedimientos para la determinación de la difusividad unidireccional del ion cloruro, en estado no estacionario, a través del concreto [1-3]. Así mismo se han realizado ensayos inter-laboratorios utilizando diferentes técnicas para caracterizar la resistencia del concreto al ingreso del ion cloruro [4]. 


\section{DEFINICIONES}

\subsection{Superficie moldeada}

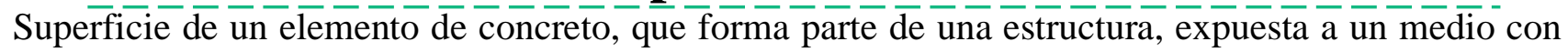
iones cloruro.

\subsection{Obtención de muestras pulverizadas de concreto}

Proceso de molienda o trituración en seco en el que se van obteniendo muestras pulverizadas correspondientes a capas finas sucesivas desde la superficie de la probeta de concreto expuesta a la disolución de cloruro. Cada muestra corresponde a una profundidad $(\mathrm{mm})$ desde la superficie.

\subsection{Contenido de cloruro}

Cantidad de cloruro soluble en ácido, determinada por análisis químico de las muestras pulverizadas de concreto, expresada en porcentaje en masa sobre la masa total de concreto.

\subsection{Perfil de cloruro}

Conjunto de pares de datos (profundidad desde la superficie - contenido de cloruro), correspondientes a las muestras obtenidas de la probeta de concreto ensayada. Normalmente el perfil se presenta en formato tabular, o en forma de representación gráfica del contenido de cloruro en función de la profundidad desde la superficie de concreto expuesta al medio conteniendo cloruro.

\subsection{Difusión}

Movimiento de moléculas o iones debido a un gradiente de concentración, es decir transporte desde una zona de alta concentración a una zona de concentración menor.

\subsection{Coeficiente de difusión}

Coeficiente de proporcionalidad entre el flujo molecular (velocidad de paso de iones cloruro) y el gradiente de concentración en la ecuación de difusión (Leyes de Fick de la difusión), [5, 6].

\subsection{Contenido inicial de cloruro $\left(\bar{C}_{i}\right)$}

Contenido de cloruro a una distancia suficientemente remota, desde la superficie expuesta de concreto, como para no haber sido influenciado por la penetración de la disolución de cloruro. Representa el contenido inicial de cloruro aportado por los componentes en el momento del amasado del concreto.

\subsection{Coeficiente de difusión en estado no estacionario $\left(D_{n s s}\right)$}

Valor del coeficiente de difusión determinado en condiciones de flujo de cloruro no constante. Dicho coeficiente incorpora los efectos de la combinación de cloruro que se produce simultáneamente a la difusión (representa la velocidad de difusión del cloruro cuando una parte del mismo está siendo combinada por las fases sólidas del concreto), [6]. 
NOTA: No debe confundirse el $D_{n s s}$ con el coeficiente de difusión en estado estacionario $\left(\mathrm{D}_{\mathrm{ss}}\right)$ que se determina en condiciones de flujo constante (ensayo en que una fina probeta de concreto se pone en contacto con dos disoluciones, una de alta concentración de cloruro y otra libre del mismo, hasta obtener un flujo constante de cloruro). Este último ensayo no se recoge en esta Recomendación Técnica. El $D_{s s}$ representa la velocidad de difusión en ausencia de combinación ya que, cuando se alcanzan las condiciones de flujo constante, el concreto no puede combinar más cloruro.

\subsection{Condición de saturación bajo vacío}

Estado de la probeta de concreto tras haber sido saturada con agua bajo vacío, como pre-tratamiento antes de comenzar el ensayo de difusión.

\section{PRINCIPIOS DEL MÉTODO}

Las probetas de concreto para el ensayo, de forma cilíndrica o cúbica, son moldeadas y curadas en cámara húmeda durante al menos 28 días.

El Anejo A indica el procedimiento a seguir cuando se desea ensayar probetas testigo extraídas de elementos de concretos preparados en laboratorio, de elementos de concreto prefabricado o de estructuras.

La probeta de concreto se divide en dos subprobetas, una de ellas, que denominaremos "sub-probeta para el perfill", se utilizará para la determinación del perfil de cloruro después de la exposición al ingreso unidireccional de cloruro $\left(\mathrm{Cl}^{-}\right)$. La otra sub-probeta se utilizará para la determinación del contenido inicial de cloruro, $C_{i}$.

La sub-probeta para el perfil se satura a vacío con agua destilada o desmineralizada, se aplica un recubrimiento adecuado sobre todas sus caras excepto una, y finalmente la cara no recubierta es expuesta a una disolución de cloruro. La exposición se lleva a cabo por inmersión completa, por contacto con la disolución contenida en un pequeño estanque conformado sobre la cara de concreto a ensayar (procedimiento que denominaremos "exposición por estanque"), o por inversión de la probeta (la cara no recubierta en dirección hacia abajo) e inmersión de dicha cara no recubierta en la disolución de cloruro (procedimiento que denominaremos "exposición por inversión”). La disolución de ensayo de referencia es una disolución acuosa al $3 \%$ en masa de $\mathrm{NaCl}$, para un periodo de ensayo de 90 días (otras concentraciones o composiciones, por ejemplo, agua de mar artificial, pueden utilizarse así como otras duraciones del periodo de exposición). El ensayo por inmersión de grandes probetas o elementos de concreto se describe en el Anejo C.

Después de los 90 días de exposición, se extraen de la sub-probeta para el perfil al menos 8 muestras de concreto pulverizado correspondientes a otras tantas finas capas paralelas a la superficie expuesta. Se determina la profundidad media de cada capa con respecto a la superficie, y se determina el contenido de cloruro soluble en ácido de cada muestra. El contenido inicial de cloruro se determina a partir de una muestra pulverizada obtenida de la otra sub-probeta reservada a tal fin.

Se realiza un análisis de regresión no lineal, ajustando por mínimos cuadrados la ecuación solución de la segunda Ley de Fick de la difusión al perfil de cloruro obtenido. De dicho análisis se obtiene la concentración superficial de cloruro $\left(C_{S}\right)$ y el coeficiente de difusión en estado no estacionario $\left(D_{n s s}\right)$.

Debido al elevado valor del coeficiente de variación, $\approx 15-30 \%$ para el $D_{n s s}$, es necesario ensayar al menos dos probetas, proporcionando los resultados obtenidos con cada probeta ensayada.

NOTA 1: El coeficiente de difusión de cloruro varía con la edad del concreto y por tanto con la duración del periodo de exposición.

NOTA 2: El ensayo de difusión descrito en esta Recomendación Técnica es válido únicamente cuando el contenido inicial de cloruro sea constante. 


\section{REACTIVOS Y APARATOS}

\subsection{Reactivos}

Deben utilizarse únicamente reactivos de calidad para análisis.

NOTA: A menos que se especifique lo contrario el término porcentaje (\%) debe interpretarse como porcentaje en masa.

\subsubsection{Hidróxido de calcio, $\mathrm{Ca}(\mathrm{OH})_{2}$}

\subsubsection{Disolución de cloruro para el ensayo de difusión}

5.1.2.1. Disolución de referencia para el ensayo de difusión

Disolver $30 \mathrm{~g}$ de $\mathrm{NaCl}$ en $970 \mathrm{~g}$ de agua destilada o desionizada de conductividad eléctrica $\leq 0.5 \mathrm{mS} \mathrm{m}^{-1}$, para obtener una disolución de $\mathrm{NaCl}$ al $3 \%$ en masa. Guardar en un recipiente limpio.

NOTA: Esta disolución de $\mathrm{NaCl}$ tiene una concentración de $\mathrm{Cl}^{-}$similar a la del agua del Océano Atlántico.

5.1.2.2. Otras disoluciones para el ensayo de difusión

Cuando se utilice una composición de la disolución de cloruro distinta a la del apartado 5.1.2.1 la composición debe ser anotada e indicada en el informe del ensayo.
NOTA 1: Se ha utilizado agua de mar natural o artificial para reflejar las condiciones de exposición de ciertas estructuras.

NOTA 2: Se han utilizado concentraciones superiores de la disolución de cloruro, tales como $16.5 \%$, y periodos de exposición más cortos (por ejemplo 35 días) para acelerar el desarrollo del perfil de cloruro.

\subsubsection{Material de recubrimiento de la probeta de hormigón}

Producto capaz de generar una película sobre la probeta de concreto suficientemente impermeable a la disolución de cloruro. Por ejemplo, resina de poliuretano de dos componentes o pintura epoxi u otro sistema de barrera equivalente.

\subsubsection{Reactivos para el análisis químico del contenido de cloruro}

Se utilizarán los reactivos necesarios de acuerdo al método de análisis seleccionado.

\subsubsection{Agua destilada o desmineralizada}

El agua a utilizar tendrá una conductividad eléctrica $\leq 0.5 \mathrm{mS} \mathrm{m}^{-1}$.

\subsection{Aparatos}

\subsubsection{Sistema de corte para concreto mediante disco de diamante refrigerado por agua}

\subsubsection{Balanza para pesar el $\mathrm{NaCl}$ y el agua \\ Precisión de $\pm 0.1 \mathrm{~g}$.}

\subsubsection{Termómetro}

Precisión de $\pm 1^{\circ} \mathrm{C}$.

\subsubsection{Cámara o recinto de temperatura controlada}

Dicha cámara debe ser capaz de mantener una temperatura de $20^{\circ} \mathrm{C} \pm 2^{\circ} \mathrm{C}$ durante el periodo de ejecución del ensayo. También podrá utilizarse un baño termostático de agua capaz de mantener la misma temperatura. 


\subsubsection{Contenedor de polietileno} con tapa de cierre hermético para la inmersión de la sub-probeta para el perfil

Este contenedor es necesario si se utiliza el método de exposición por inmersión o inversión, véanse Secciones 7.2.2 y 7.2.4. El cociente entre el volumen de la disolución de cloruro y la superficie expuesta de la probeta de concreto, debe ser $\geq 12.5 \mathrm{ml}$ por $\mathrm{cm}^{2}$ de superficie expuesta. El contenedor podrá alojar más de una probeta siempre que se respete el valor mínimo del cociente entre el volumen de disolución y la superficie expuesta. El valor de dicho cociente será anotado y reflejado en el informe del ensayo.

NOTA: Durante el ensayo la concentración de cloruro de la disolución de exposición va disminuyendo debido al ingreso de $\mathrm{Cl}^{-}$en las probetas de concreto. La velocidad de disminución de la concentración dependerá del valor del cociente entre el volumen de la disolución y la superficie de concreto expuesta. Si se está ensayando un número de probetas que requiere la utilización de varios contenedores, es necesario que el valor del cociente entre el volumen de la disolución y la superficie de concreto expuesta sea el mismo en todos los contenedores.

\subsubsection{Material para conformar un pequeño estanque sobre la}

\section{cara de concreto a ensayar}

Este material será necesario si se utiliza el método de exposición por estanque descrito en la Sección 7.2.3. Puede utilizarse lámina de plástico (por ejemplo PVC) de espesor aproximado de $2 \mathrm{~mm}$, o piezas comerciales de plástico de forma y dimensiones adecuadas (tubos), para conformar un recipiente estanco que contendrá la disolución de cloruro en contacto con la cara de la probeta a ensayar. Debe utilizarse un elemento sellador o adhesivo adecuado, por ejemplo silicona, para evitar fugas de la disolución de ensayo. El estanque tendrá una sección constante y debe permitir que la disolución de cloruro alcance una altura mínima de $125 \mathrm{~mm}$ sobre la cara de la probeta.

\subsubsection{Equipamiento para la extracción y recogida de} muestras de concreto pulverizado correspondientes a capas de espesor menor de $2 \mathrm{~mm}$

Sistema equipado con una broca diamantada o herramienta que permita producir un lijado en dirección perpendicular a la superficie de concreto expuesta, de tal modo que se obtienen muestras de concreto pulverizado correspondientes a finas capas sucesivas y paralelas a la superficie expuesta. La superficie de lijado será $\geq 40 \mathrm{~cm}^{2}$, excluyendo siempre las superficies de concreto cuya distancia al borde del área de ensayo sea $<10$ $\mathrm{mm}$.

\subsubsection{Pistola de aire comprimido \\ o equipo de soplado de aire}

Se utiliza para limpiar de polvo el equipamiento y la probeta de concreto después de la obtención de cada muestra de concreto pulverizado.

\subsubsection{Bolsas de plástico para la recogida de las muestras de concreto pulverizado}

Deben permitir anotaciones tales como la denominación de la muestra y la profundidad desde la superficie expuesta.

\subsubsection{Equipamiento de análisis químico para la determinación del contenido de cloruro soluble \\ en ácido de las muestras de concreto pulverizado}

Se utilizarán los aparatos y material de laboratorio necesarios de acuerdo al método de análisis seleccionado.

\subsubsection{Calibre para la determinación de la profundidad media de las muestras de concreto pulverizado}

Precisión de $\pm 0.1 \mathrm{~mm}$. 
5.2.12. Contenedor para vacío

Debe tener capacidad para contener al menos

tres probetas de concreto.

\subsubsection{Bomba de vacío}

Debe ser capaz de mantener una presión absoluta menor de 50 mbar $(5 \mathrm{kPa})$ en el contenedor para vacío.

\section{PREPARACIÓN DE LAS PROBETAS}

\subsection{Preparación de las sub-probetas}

El tamaño de las probetas debe seleccionarse de tal manera que tras el tallado de las mismas, la dimensión mínima de la subprobeta utilizada para la obtención del perfil de cloruro sea de al menos tres veces el tamaño máximo nominal del agregado grueso. Se moldean al menos dos probetas, que pueden ser cilíndricas de diámetro mínimo $100 \mathrm{~mm}$ o cúbicas de arista mínima $100 \mathrm{~mm}$. Se curan las probetas durante un periodo mínimo de 28 días en un baño de agua a $20^{\circ} \mathrm{C}$ $\pm 2^{\circ} \mathrm{C}$.

NOTA 1: El objetivo del ensayo es determinar la resistencia potencial de una mezcla de concreto al ingreso de cloruro. Si el concreto contiene materiales cementantes secundarios, tales como ceniza volante o escoria siderúrgica, puede resultar más adecuado incrementar la edad de las probetas al inicio del ensayo, ya que es conocido que la resistencia al ingreso de cloruro puede aumentar significativamente para edades superiores a los 28 días.

Después de al menos 28 días de curado, cada cilindro o cubo se corta en dos sub-probetas utilizando el sistema de corte para concreto refrigerado por agua. Las probetas cilíndricas se cortan en dirección paralela a la superficie plana, y las cúbicas se cortan en dirección paralela a la superficie superior (fratasada/áspera), tal como se muestra en la Figura 1. La superficie de ensayo no debe tener huecos ni fisuras visibles. Ninguna dimensión de las sub-probetas utilizadas para la determinación del perfil de cloruro debe ser menor que el triple del tamaño máximo nominal del agregado. Una sub-probeta (denominada la "sub-probeta para el perfil") se utiliza para determinar el perfil de cloruro, y la otra sub-probeta (denominada "subprobeta para el cloruro inicial") se utiliza para determinar el contenido inicial de cloruro. Este contenido inicial de cloruro se considera equivalente al contenido de cloruro del concreto moldeado. Se utilizan siempre las caras adyacentes (generadas en el corte) para la obtención tanto del perfil como del cloruro inicial.

NOTA 2: Cuando se requiera estudiar el efecto de una superficie moldeada sobre el perfil de cloruro, es posible utilizar una de las superficies moldeadas de una probeta cúbica como superficie de ensayo. Sin embargo, los resultados obtenidos en tales condiciones son difíciles de interpretar debido a los diferentes contenidos de pasta de cemento y de cloruro presentes en la superficie moldeada. La utilización de esta variante del ensayo debe indicarse en la cláusula $9 \mathrm{~m}$ ) del informe, ya que esta es una condición de ensayo no habitual.
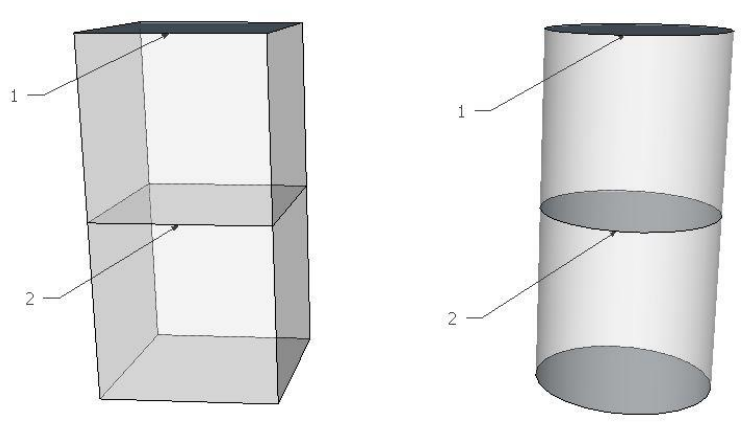

Clave:

1. Superficie fratasada/áspera

2. Corte de separación de las sub-probetas que genera las superficies de ensayo

Figura 1. Preparación de las probetas para ensayo 
Después del corte, la sub-probeta para el cloruro inicial se ensayará inmediatamente o se colocará en el interior de una bolsa de plástico sellada de dimensiones ligeramente superiores a las de la subprobeta.

Cuando sea necesario, las sub-probetas se pueden cortar para reducir su tamaño con el fin de facilitar su manejo, pero la dimensión mínima de la sub-probeta para el perfil nunca debe ser inferior al triple del tamaño máximo nominal del agregado.

\subsection{Acondicionamiento y preparación de la probeta para la obtención del perfil de cloruro}

\subsubsection{Saturación a vacío de las sub-probetas para perfil}

Después del corte de las sub-probetas para perfil, éstas se saturan con agua bajo vacío. El Anejo B muestra un esquema típico para la operación de saturación a vacío. Se colocan las sub-probetas para perfil en el contenedor para vacío y se reduce la presión absoluta a un valor entre 10 y 50 mbar ( 1 a $5 \mathrm{kPa}$ ), valor que debe obtenerse en unos pocos minutos tras cerrar el contenedor. Mantener esta presión absoluta durante 3 horas y entonces, manteniendo la bomba de vacío en funcionamiento, llenar el contenedor con agua destilada o desmineralizada de tal manera que todas las sub-probetas para perfil queden sumergidas. Se mantiene la presión absoluta reducida durante una hora adicional antes de permitir la entrada de aire en el contenedor.

$\mathrm{Se}$ dejan las sub-probetas para perfil sumergidas, bien en la misma agua o en un tanque de agua normal para curado, hasta que comience la operación de sellado de superficies de la probeta, véase Anejo D.2.

\subsubsection{Sellado de las superficies distintas a la de exposición}

Comenzar el sellado antes de 24 horas después de completar la saturación a vacío. Todas las superficies de la sub-probeta para perfil serán selladas, excepto la cara cortada, véase Anejo C para una excepción. Después de sellar las superficies, se colocan las sub-probetas sumergidas en una disolución saturada de hidróxido de calcio durante 18 horas.

NOTA 1: El propósito del sellado de todas las superficies, excepto la expuesta a la disolución de cloruro, es el de asegurar que el ingreso de cloruro en el concreto se produce por un mecanismo de difusión unidireccional pura y no por un mecanismo mixto de difusión y otros procesos de transporte, tales como la absorción capilar.

El requisito de sellado de superficies puede ser satisfecho de diferentes maneras. Las siguientes técnicas han sido establecidas como adecuadas.

a) Técnica de sellado utilizable para cualquier método de exposición (inmersión, estanque o inversión)

La sub-probeta para perfil se seca en laboratorio hasta un estado de superficie "blanca-seca".

NOTA 2: Este secado requiere normalmente de 2 a 4 horas.

Todas las superficies, excepto la cara a exponer a la disolución de cloruro, se recubren con una capa de epoxi o poliuretano, cera de parafina, o producto equivalente, asegurándose que la cara de ensayo se mantiene libre del material de recubrimiento y que el resto de caras han quedado perfectamente selladas. El material de recubrimiento se aplicará y curará siguiendo las recomendaciones del fabricante.

NOTA 3: No todas las resinas epoxi o de poliuretano son adecuadas para esta aplicación.

b) Técnica alternativa para exposición por estanque

Esta técnica es únicamente utilizable para la exposición por estanque. Secar las superficies con un paño humedecido para eliminar el agua libre y recubrir todas las superficies, excepto la cara a exponer a la disolución de cloruro, con cinta eléctrica aislante asegurando un solape suficiente de las juntas.

\subsubsection{Sub-probeta para exposición por inmersión}

Después del almacenamiento en la disolución saturada de hidróxido de calcio, la sub-probeta se transfiere directamente al recipiente de exposición por inmersión sin secar la superficie. La Figura 2 muestra un esquema adecuado para este tipo de exposición. 


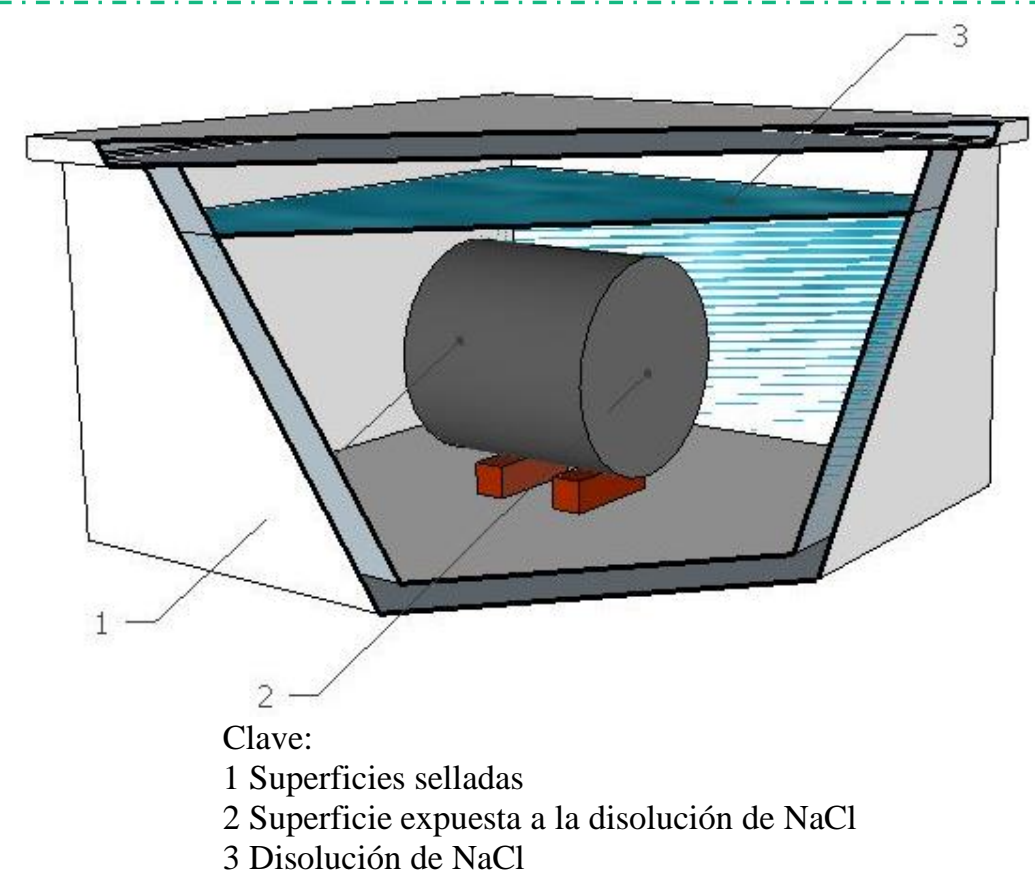

Figura 2. Ejemplo de montaje para la exposición por inmersión

\subsubsection{Sub-probeta para exposición por estanque}

Después del almacenamiento en la disolución saturada de hidróxido de calcio, se sella el estanque a la superficie de ensayo de la subprobeta para perfil, de tal manera que se eviten las fugas de disolución de cloruro. La Figura 3 muestra un esquema adecuado, debiendo tenerse en cuenta que el volumen de líquido en el estanque debe cumplir la condición expresada en la Sección 5.2.6. El diámetro del tubo utilizado debe ser de $5 \mathrm{~mm}$ a $10 \mathrm{~mm}$ menor que el diámetro de la sub-probeta para facilitar un sellado perfecto sin fugas de la disolución, siempre permitiendo cumplir las condiciones enunciadas en la Sección 5.2.7. El borde externo entre el tubo de plástico y la subprobeta se sella para prevenir fugas. Así mismo se sella la pequeña superficie de concreto que pueda quedar entre la cara exterior del tubo y el borde de la sub-probeta para prevenir que el concreto en esa zona se pueda secar durante el ensayo de difusión.

NOTA: En la zona del borde de la sub-probeta el ingreso de cloruro no es unidireccional.

Una técnica alternativa para formar el estanque es utilizar un tubo de diámetro ligeramente superior al de la sub-probeta y una junta de caucho entre el tubo y el borde de la subprobeta.

Clave:

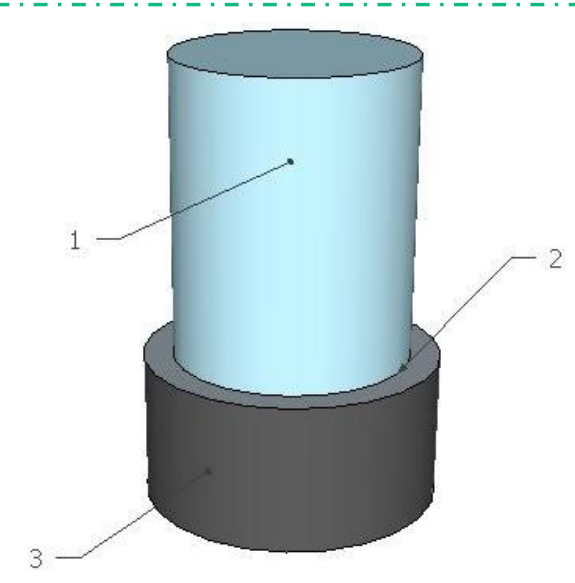

1 Estanque

2 Sellado

3 Sub-probeta para perfil, con recubrimiento

Figura 3. Ejemplo de montaje para la exposición por estanque 


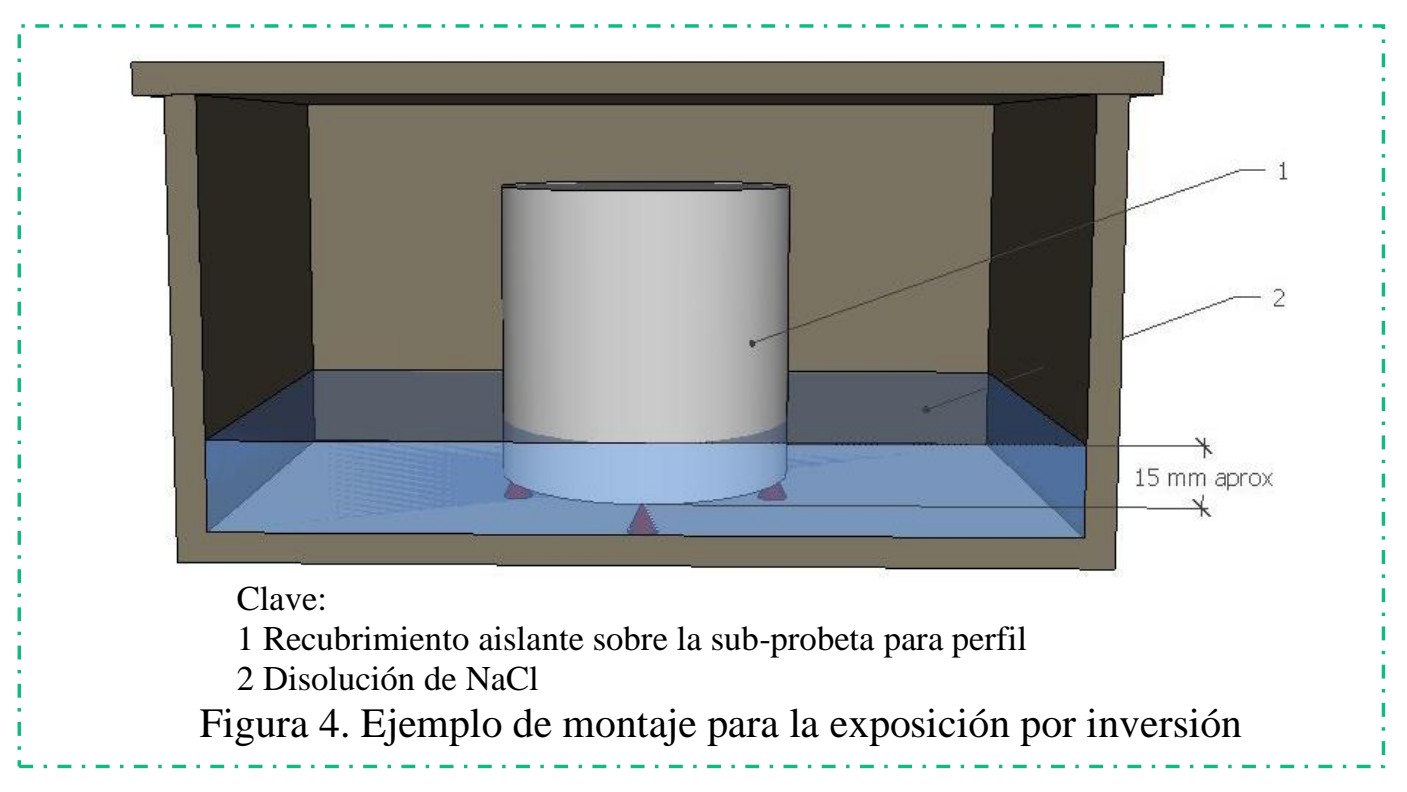

\subsubsection{Sub-probeta para exposición por inversión}

Después del sellado según lo indicado en la Sección 6.2.2 y el almacenamiento en la disolución saturada de hidróxido de calcio, la sub-probeta es transferida directamente al recipiente de exposición por inversión sin secar la superficie. La Figura 4 muestra un esquema adecuado para este tipo de exposición. Para esta modalidad del ensayo también debe cumplirse el requisito de la Sección 5.2.5, es decir el cociente entre el volumen de la disolución de cloruro y la superficie expuesta de la probeta de concreto, debe ser $\geq 12.5 \mathrm{ml}$ por $\mathrm{cm}^{2}$ de superficie expuesta.

\section{PROCEDIMIENTO}

\subsection{Condiciones de exposición}

\subsubsection{Disolución de cloruro para el ensayo de difusión}

A menos que se especifique otra cosa, la disolución para el ensayo de difusión será una disolución de $\mathrm{NaCl}$ al 3\% en masa, tal como se especifica en la Sección 5.1.2.1. Si se utiliza una disolución distinta a la de referencia (véase 5.1.2.2), ello debe ser indicado en el informe. La concentración de la disolución de exposición debe ser determinada y anotada al finalizar el ensayo.

NOTA 1: Cuando el ensayo esté relacionado con el uso del concreto en unas condiciones específicas de exposición, la disolución de cloruro debe reflejar dichas condiciones teniendo en cuenta la disminución esperable de la concentración de cloruro durante el ensayo de difusión, véase Anejo D.3.

NOTA 2: Durante el periodo de ensayo la concentración de la disolución de cloruro disminuirá. El volumen de dicha disolución ha sido seleccionado para que ésta no tenga que ser renovada durante un ensayo de duración 90 días. Si se requiere utilizar un periodo de ensayo más largo, la disolución de cloruro deberá ser reemplazada en intervalos de 91 días.

NOTA 3: La solución habitual de la segunda Ley de Fick está basada en la condición de contorno de que la concentración externa de cloruro permanece constante durante el ensayo de difusión. En las condiciones normales de ensayo, el error introducido al suponer que la concentración de cloruro se mantiene constante e igual a la concentración inicial es pequeño.

\subsubsection{Temperatura de exposición}

La temperatura de la cámara o recinto o baño termostático, donde se mantengan los contenedores de las sub-probetas para perfil expuestas mediante los procedimientos de inmersión o inversión, o bien las sub-probetas expuestas por estanque, debe mantenerse en un valor de $20^{\circ} \mathrm{C} \pm 2^{\circ} \mathrm{C}$, confirmando dicho valor diariamente y tanto el valor medio como el rango de temperaturas durante el periodo de duración del ensayo. 


\subsection{Método de exposición}

\subsubsection{General}

La superficie expuesta (superficie de corte) de la sub-probeta para perfil debe estar en contacto directo con la disolución de exposición al cloruro bien por inmersión, estanque o inversión. La edad de la sub-probeta en el momento de comenzar la exposición al cloruro debe ser anotada e incorporada al informe.

\subsubsection{Inmersión}

Las sub-probetas para perfil serán colocadas en el contenedor previsto para inmersión, llenando dicho recipiente completamente con la disolución y sellándolo. El contenedor sellado será colocado en la cámara de temperatura controlada o en el baño de agua a $20^{\circ} \mathrm{C} \pm 2^{\circ} \mathrm{C}$.

\subsubsection{Estanque}

Una vez colocado el estanque sobre la cara expuesta de la sub-probeta para perfil, este se llena completamente con la disolución de cloruro y se sella con una película de plástico. Los conjuntos completos (sub-probeta y estanque) se colocan en la cámara de temperatura controlada a $20 \pm 2^{\circ} \mathrm{C}$.

\subsubsection{Inversión}

Las sub-probetas para perfil se invierten boca abajo y se ponen en contacto con la disolución de cloruro. Deben fijarse de tal manera que se asegure que la superficie completa de la cara expuesta esté y permanezca en contacto con la disolución, por ejemplo, colocando las probetas sobre tres apoyos puntiagudos situados por debajo de la superficie de la disolución de cloruro, véase la Figura 4.

La altura del líquido sobre el nivel de la cara expuesta de la sub-probeta debe mantenerse en un valor de unos $15 \mathrm{~mm}$. Las sub-probetas deben colocarse de tal modo que se minimice el riesgo de que queden burbujas de aire debajo de la superficie de concreto expuesta. El contenedor se sella para evitar la evaporación y se coloca en la cámara de temperatura controlada o en el baño de agua a $20^{\circ} \mathrm{C} \pm 2^{\circ} \mathrm{C}$.

\subsection{Periodo de exposición}

El periodo de exposición de referencia es de 90 días.

\subsection{Determinación del contenido inicial de cloruro $(\mathrm{C} i)$}

Se recupera la sub-probeta para el contenido inicial de cloruro de su bolsa de plástico. Sobre la superficie cortada se realiza un desgaste por lijado superficial, (sección 5.2.7), de una capa de espesor mínimo $1 \mathrm{~mm}$ descartando el concreto pulverizado obtenido y limpiando con aire comprimido la superficie resultante. Sobre la superficie limpia se realiza un nuevo desgaste por lijado superficial hasta obtener una muestra de $20 \mathrm{~g}$ de concreto pulverizado para análisis de cloruro. Se determina el contenido de cloruro soluble en ácido de la muestra, expresándolo como \% referido a masa de concreto. Dicho valor es designado como $C_{\mathrm{i}}$.

El valor de $C_{\mathrm{i}}$ puede ser determinado a partir de una sola sub-probeta por cada mezcla de concreto.

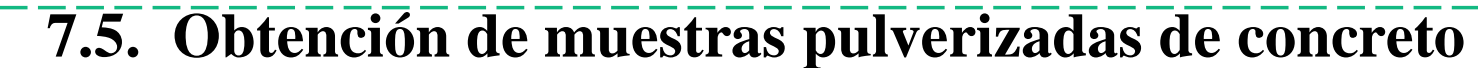

La muestra correspondiente a cada capa debe contener un mínimo de $5 \mathrm{~g}$ de concreto pulverizado, y la capa más superficial tendrá un espesor mínimo de $1.0 \mathrm{~mm}$. Los espesores del resto de capas deben ajustarse de acuerdo al perfil de cloruro esperable, de tal manera que haya un mínimo de 6 puntos entre la superficie de concreto expuesta y la profundidad a la que el contenido de cloruro sea ligeramente superior a $C_{\mathrm{i}}$. 
La Tabla 1 recoge los intervalos recomendados de espesor para las muestras a obtener de concretos de cemento Portland, mientras que la Tabla 2 hace lo mismo para el caso de concretos conteniendo ceniza volante, escoria siderúrgica o humo de sílice. Dichas tablas están basadas en experiencia obtenida de ensayos de probetas curadas durante 28 días y expuestas a la disolución de cloruro durante 90 días.

Tabla 1. Intervalos de profundidad recomendados $(\mathrm{mm})$ para la obtención de muestras pulverizadas de concreto de cemento Portland puro

\begin{tabular}{|c|c|c|c|c|c|c|}
\hline $\begin{array}{c}\text { Relación } \\
\text { agua/cemento }\end{array}$ & 0.30 & 0.35 & 0.40 & 0.50 & 0.60 & 0.70 \\
\hline Capa 1 & $0 \sim 1$ & $0 \sim 1$ & $0 \sim 1$ & $0 \sim 1$ & $0 \sim 1$ & $0 \sim 1$ \\
\hline Capa 2 & $1 \sim 2$ & $1 \sim 2$ & $1 \sim 3$ & $1 \sim 3$ & $1 \sim 3$ & $1 \sim 5$ \\
\hline Capa 3 & $2 \sim 3$ & $2 \sim 3$ & $3 \sim 5$ & $3 \sim 5$ & $3 \sim 6$ & $5 \sim 10$ \\
\hline Capa 4 & $3 \sim 4$ & $3 \sim 5$ & $5 \sim 7$ & $5 \sim 8$ & $6 \sim 10$ & $10 \sim 15$ \\
\hline Capa 5 & $4 \sim 6$ & $5 \sim 7$ & $7 \sim 10$ & $8 \sim 12$ & $10 \sim 15$ & $15 \sim 20$ \\
\hline Capa 6 & $6 \sim 8$ & $7 \sim 9$ & $10 \sim 13$ & $12 \sim 16$ & $15 \sim 20$ & $20 \sim 25$ \\
\hline Capa 7 & $8 \sim 10$ & $9 \sim 12$ & $13 \sim 16$ & $16 \sim 20$ & $20 \sim 25$ & $25 \sim 30$ \\
\hline Capa 8 & $10 \sim 12$ & $12 \sim 16$ & $16 \sim 20$ & $20 \sim 25$ & $25 \sim 30$ & $30 \sim 35$ \\
\hline
\end{tabular}

Tabla 2. Intervalos de profundidad recomendados $(\mathrm{mm})$ para la obtención de muestras pulverizadas de concreto conteniendo escoria siderúrgica, ceniza volante o humo de sílice

\begin{tabular}{|c|c|c|c|c|c|c|}
\hline $\begin{array}{c}\text { Relación } \\
\text { agua/cemento }^{\text {a) }}\end{array}$ & 0.30 & 0.35 & 0.40 & 0.50 & 0.60 & 0.70 \\
\hline Capa 1 & $0 \sim 1$ & $0 \sim 1$ & $0 \sim 1$ & $0 \sim 1$ & $0 \sim 1$ & $0 \sim 1$ \\
\hline Capa 2 & $1 \sim 2$ & $1 \sim 2$ & $1 \sim 2$ & $1 \sim 3$ & $1 \sim 3$ & $1 \sim 3$ \\
\hline Capa 3 & $2 \sim 3$ & $2 \sim 3$ & $2 \sim 3$ & $3 \sim 5$ & $3 \sim 5$ & $3 \sim 6$ \\
\hline Capa 4 & $3 \sim 4$ & $3 \sim 4$ & $3 \sim 5$ & $5 \sim 7$ & $5 \sim 8$ & $6 \sim 10$ \\
\hline Capa 5 & $4 \sim 5$ & $4 \sim 6$ & $5 \sim 7$ & $7 \sim 10$ & $8 \sim 12$ & $10 \sim 15$ \\
\hline Capa 6 & $5 \sim 6$ & $6 \sim 8$ & $7 \sim 9$ & $10 \sim 13$ & $12 \sim 16$ & $15 \sim 20$ \\
\hline Capa 7 & $6 \sim 8$ & $8 \sim 10$ & $9 \sim 12$ & $13 \sim 16$ & $16 \sim 20$ & $20 \sim 25$ \\
\hline Capa 8 & $8 \sim 10$ & $10 \sim 12$ & $12 \sim 16$ & $16 \sim 20$ & $20 \sim 25$ & $25 \sim 30$ \\
\hline
\end{tabular}

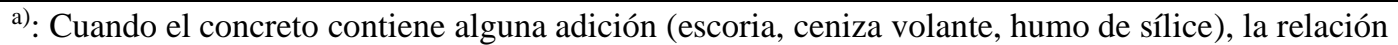
agua/cemento se sustituye por la relación $\mathrm{w} /(\mathrm{c}+\mathrm{k}$ a). Donde $\mathrm{w}$ es el contenido de agua, $\mathrm{c}$ es el contenido de cemento Portland, a es el contenido de la adición, (contenidos en $\mathrm{kg} \mathrm{m}^{-3}$ ), y k es el coeficiente de eficacia de la adición, véase por ejemplo referencia [8].

NOTA 1: Los valores de las Tablas 1 y 2 podrían no ser apropiados para concretos más maduros o concreto extraído de estructuras existentes.

NOTA 2: En circunstancias normales todas las siete capas serían incluidas en el perfil (el valor correspondiente a la capa superficial no se incluye en el perfil). El criterio de extraer muestras correspondientes a un mínimo de ocho capas tiene como finalidad evitar que el resultado del ensayo sea invalidado si un punto del perfil es descartado por ser considerado un valor atípico, véase Sección 8.

NOTA 3: Pueden encontrarse más detalles acerca del proceso de obtención de muestras pulverizadas de concreto en la referencia [7]. 
Al finalizar la extracción de muestras, se guarda el resto de la sub-probeta para perfil en una bolsa de plástico sellada de dimensiones ligeramente superiores a las de la sub-probeta hasta que finalice el ensayo. Si el contenido de cloruro en la capa más profunda es $>\left(C_{\mathrm{i}}+\right.$ $0.015)$, extraer muestras correspondientes a capas adicionales más profundas hasta que se pueda establecer un perfil completo. Para asegurar que se ha conseguido establecer un perfil completo, es decir que la disolución de cloruro no ha penetrado de forma completa la sub-probeta para perfil, la última capa debe corresponder a una profundidad $\leq$ (espesor total de la sub-probeta $-10 \mathrm{~mm}$ ).

El proceso de extracción de muestras debe realizarse en seco, y el desgaste por lijado debe realizarse sobre una superficie $\geq 40 \mathrm{~cm}^{2}$, cuyo borde estará situado a una distancia $\geq 10 \mathrm{~mm}$ al borde de la zona de contacto con la disolución. Esta última precaución tiene como objetivo evitar efectos de borde y posibles influencias negativas de los recubrimientos o material de sellado.

La sub-probeta para perfil se fija de forma segura en posición paralela al borde de la broca o herramienta de lijado superficial, y una bolsa adecuada, véase 5.2.9, se coloca en posición para la recogida de la muestra pulverizada.
Cada capa debe producir un mínimo de $5 \mathrm{~g}$ de concreto pulverizado. Después de la extracción y retirada de cada muestra, se debe limpiar con aire comprimido el equipo y la superficie de la sub-probeta de cualquier resto de polvo; entonces se toman medidas, con el calibre (precisión $\pm 0.1 \mathrm{~mm}$ ), de la profundidad alcanzada después de extraer la última muestra. Dicha profundidad se calcula como la media de cinco medidas, tomadas en posiciones equidistantes sobre la circunferencia o perímetro del área de muestreo. Se toma nota del intervalo de profundidad de la capa extraída, que comienza en la profundidad alcanzada en la extracción de la muestra anterior y termina en la profundidad alcanzada en la extracción de la presente muestra.

Las muestras de concreto pulverizado se guardan en bolsas de plástico rotuladas, para ser posteriormente analizadas para obtener su contenido de cloruro. Cada bolsa debe ser rotulada con la referencia de la sub-probeta, intervalo de profundidad de la muestra y fecha de extracción.

Se calcula la profundidad media correspondiente a cada muestra, que corresponde al centro de su intervalo de profundidad, y se expresa en $\mathrm{mm}$ con una precisión de $\pm 0.2 \mathrm{~mm}$.

\subsection{Análisis químico de los contenidos de cloruro}

Se determina el contenido de cloruro soluble en ácido de cada muestra de concreto pulverizado, de acuerdo a la norma o procedimiento de análisis considerado más adecuado, véanse referencias [9-12]. Los resultados se expresan como porcentaje relativo a la masa de concreto.

\section{TRATAMIENTO MATEMÁTICO DEL PERFIL DE CLORURO Y EXPRESIÓN DE RESULTADOS}

El contenido de cloruro de la primera capa de concreto, es decir la capa superficial, se descarta para el análisis por regresión.

El contenido de cloruro de la segunda capa de concreto $(\mathrm{j}=2)$, junto a la profundidad media de dicha capa, constituyen el primer punto a utilizar en el análisis por regresión.

Se determina la primera capa de concreto para la que el contenido de cloruro medido alcanza un valor entre $C_{\mathrm{i}}$ y $C_{\mathrm{i}}+0.015$, donde $C_{\mathrm{i}}$ es el contenido inicial de cloruro del concreto determinado como se indica en la Sección 7.4. La primera capa de concreto que muestra un contenido de cloruro $C_{\mathrm{i}} \leq C \leq C_{\mathrm{i}}+0.015$ constituye el último punto $(\mathrm{j}=\mathrm{n})$ a utilizar en el análisis de regresión y se le denomina el "punto cero". Si este punto no ha sido encontrado, deben extraerse más muestras de concreto 
pulverizado correspondientes a capas más profundas, hasta que se alcance el punto cero. Los datos correspondientes a capas más profundas que el punto cero se excluyen del análisis de regresión, al igual que la capa superficial.

Para verificar la idoneidad del ajuste del modelo matemático elegido al conjunto de datos disponible, es decir al perfil de cloruro obtenido, se calcula el coeficiente de correlación $\left(R^{2}\right)$ del ajuste.

El coeficiente de correlación $R^{2}$ deberá ser > 0.950 para tener certeza de que el perfil de cloruro obtenido puede ser modelado adecuadamente mediante la Ecuación (1), y para poder considerar confiables los resultados del proceso de regresión expresados en términos de $D_{\text {nss }}$ y $C_{\text {s. }}$.

Para incrementar el nivel de confianza, expresado por el valor de $R^{2}$, se pueden descartar los datos correspondientes a puntos sospechosos, teniendo en cuenta que en el análisis de regresión debe utilizarse siempre un mínimo de 6 puntos, que el contenido de cloruro de la segunda capa debe ser siempre incluido y que no se descartan datos de puntos sucesivos.

NOTA 1: Para conseguir el número de puntos necesarios, puede ser necesario realizar una nueva extracción de muestras de una subprobeta gemela con más capas, o extraer más muestras de la sub-probeta original.

Se realiza el ajuste de la Ecuación (1) a los datos correspondientes a los puntos relevantes del perfil de cloruro, mediante regresión no lineal por el método de mínimos cuadrados. De dicho ajuste se obtendrán los valores del contenido de cloruro en la superficie de concreto expuesta $\left(C_{\mathrm{s}}\right)$ y del coeficiente de difusión en estado no estacionario $\left(D_{\mathrm{nss}}\right)$. La Figura 5 muestra como ejemplo un perfil de cloruro (puntos) así como la curva calculada (línea continua) a partir del ajuste de la Ecuación (1) a dicho conjunto de datos. Siempre debe tenerse en cuenta que la capa superficial $(j=1)$ del perfil se omite para el ajuste.

$$
C_{x}=C_{i}+\left(C_{S}-C_{i}\right)\left(1-\operatorname{erf}\left[\frac{x}{2 \sqrt{D_{n s s} t}}\right]\right)
$$

\section{Donde:}

$C_{\mathrm{x}}$ es el contenido de cloruro correspondiente a la profundidad $x$ al cabo de un tiempo $t$, expresado en $\%$ referido a masa de concreto

$C_{\mathrm{s}}$ es el contenido de cloruro calculado correspondiente a la superficie de concreto expuesta, expresado en \% referido a masa de concreto

$C_{\mathrm{i}}$ es el contenido inicial de cloruro del concreto (medido), expresado en $\%$ referido a masa de concreto

$x$ es la profundidad, relativa a la superficie expuesta, de cada punto, expresada en $\mathrm{m}$

$D_{\text {nss }}$ es el coeficiente de difusión en estado no estacionario, expresado en $\mathrm{m}^{2} \mathrm{~s}^{-1}$

$t$ es el tiempo de exposición, expresado en $\mathrm{s}$ erf es la función error definida en la Ecuación (2)

$$
\operatorname{erf} z=\frac{2}{\sqrt{\pi}} \int_{0}^{z} \exp \left(-u^{2}\right) d u
$$

Los valores de erf $z$ se pueden encontrar en paquetes de software ampliamente accesibles.

NOTA 2: Los valores de $D_{\text {nss }}$ y $C_{\text {s }}$ obtenidos del ajuste no deben utilizarse para estimar la penetración de cloruro en condiciones distintas a las utilizadas en el ensayo.

NOTA 3: Los resultados de este ensayo pueden ser expresados de diferentes maneras, por ejemplo también podrían expresarse en términos de un parámetro de penetración de cloruro o de la profundidad a la que se alcanza un contenido de cloruro igual al contenido crítico para la corrosión del acero.

El ajuste por mínimos cuadrados permite obtener la combinación de los valores más idóneos para $D_{\text {nss }}$ y $C_{\mathrm{s}}$. De esa manera la línea de regresión ajustada por mínimos cuadrados, (línea continua en la Figura 5), es aquélla que presenta el valor más pequeño posible para la suma de los cuadrados de los residuales, expresada como $S\left(C_{\mathrm{m}, \mathrm{j}}-C_{\mathrm{r}, \mathrm{j}}\right)^{2}$, siendo $C_{\mathrm{m}, \mathrm{j}}$ el contenido de cloruro medido para la capa de concreto j y $C_{r, j}$ el contenido de cloruro calculado para la capa j mediante la Ecuación (1).

Para la ejecución del análisis de regresión la opción "solver", disponible en la mayoría de los programas comerciales de hoja de cálculo, 
proporciona un procedimiento práctico y conveniente para minimizar $\sum_{j=2}^{j=n}\left(C_{m, j}-C_{r, j}\right)^{2}$.

El coeficiente de correlación del ajuste, $R^{2}$, debe ser también calculado.

NOTA 4: La mayor parte de paquetes comerciales de análisis por regresión proporcionan el coeficiente de correlación como uno de los resultados del cálculo.

Si el coeficiente de correlación no es mayor de 0.950, deben manufacturarse $\mathrm{y}$ ensayarse nuevas probetas hasta alcanzar un nivel de confianza aceptable.

NOTA 5: En la norma europea EN 1239011:2015 (Annex F), referencia [1], puede encontrarse un número de ejemplos de perfiles de cloruro y los valores calculados de $D_{\text {nss }}, C_{\mathrm{s}}$ y $R^{2}$ calculados por los miembros del comité redactor de dicha norma europea. Estos ejemplos pueden ser utilizados para comprobar que el software y el método de cálculo utilizados conducen a valores iguales a los obtenidos por otros expertos.

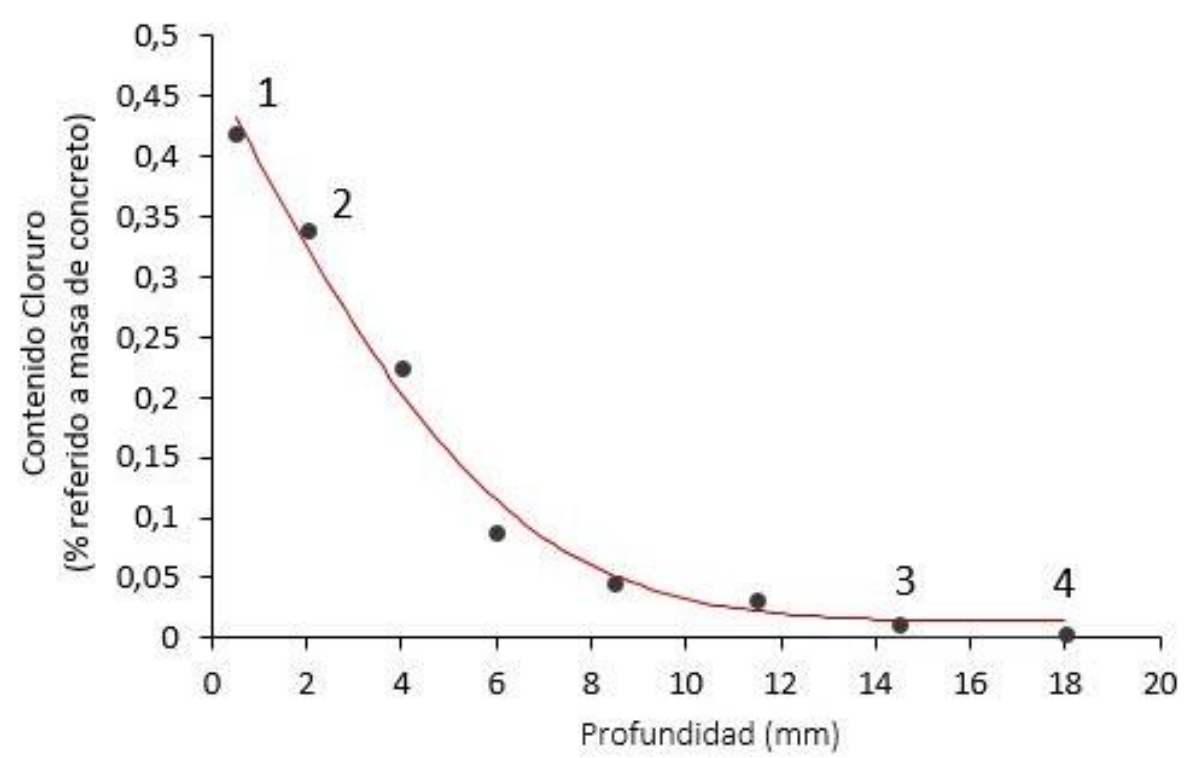

Clave:

1: El primer punto siempre es excluido para el análisis por regresión

2: Este es el primer punto utilizado para el análisis por regresión

3: El "punto cero"

4: Todos los puntos posteriores al "punto cero" se excluyen para el análisis por regresión

Figura 5. Ejemplo de perfil de cloruro: puntos: perfil experimental, línea:

perfil calculado mediante regresión no lineal con ajuste por mínimos cuadrados

\section{INFORME DEL ENSAYO}

El informe del ensayo debe incluir lo siguiente:

a. identificación de las probetas de ensayo;

b. descripción de las probetas, incluyendo su edad al comienzo del ensayo, si se conoce;

c. fecha del informe y del comienzo del ensayo;

d. duración del ensayo;

e. descripción de la disolución de exposición al cloruro, si es diferente a la disolución de $\mathrm{NaCl}$ al $3 \%$ en masa;

f. método de exposición (por inmersión, estanque o inversión);

g. temperatura media y valores más bajo y más alto de la temperatura de la disolución de exposición al cloruro;

h. volumen de la disolución de cloruro por superficie de concreto expuesta $\left(\mathrm{ml} \mathrm{cm}^{-2}\right)$

i. concentraciones inicial y final de $\mathrm{NaCl}$ en la disolución de ensayo de cloruro;

j. representación gráfica de cada perfil de cloruro, indicando los puntos incluidos en el análisis, 
los puntos excluidos y las razones para su exclusión, el perfil calculado y los valores calculados de $D_{\mathrm{nss}}, C_{\mathrm{s}}$ y $R^{2}$.

k. Cuando se ensaye más de una sub-probeta, el valor medio del coeficiente de difusión en estado no estacionario $D_{\text {nss, }}$ y de la concentración de cloruro en la superficie expuesta, $C_{\mathrm{s}}$.

1. Cualquier desviación del procedimiento descrito en esta Recomendación Técnica;

m. una declaración de la persona técnicamente responsable del ensayo de que este fue realizado de acuerdo con el procedimiento de esta Recomendación Técnica, excepto lo reflejado en el apartado 1).

\section{PRECISIÓN}

Los datos de precisión, recogidos en la Tabla 3, han sido tomados de la norma europea EN 1239011:2015, véase referencia [1]. Estos datos se refieren a una sola determinación del coeficiente de difusión y la concentración de cloruro en la superficie de concreto. Cuando se dispone de más de un resultado del ensayo, la precisión es el valor indicado en la Tabla 3 dividido por $\sqrt{ } \mathrm{n}$.

\begin{tabular}{|c|c|c|c|c|c|}
\hline \multirow{2}{*}{ Parámetro } & \multirow{2}{*}{ Nivel } & \multicolumn{2}{|c|}{ Repetibilidad } & \multicolumn{2}{|c|}{ Reproducibilidad } \\
\hline & & sr & $\mathbf{r}$ & $\mathbf{s R}$ & $\mathbf{R}$ \\
\hline $\begin{array}{c}D_{n s s}(\mathrm{E}-12) \\
\mathrm{m}^{2} / \mathrm{s}\end{array}$ & 5.09 & 1.17 & 3.27 & 1.54 & 4.31 \\
\hline $\begin{array}{l}\mathrm{C}_{\mathrm{s}} \% \text { (referido } \\
\text { a masa de } \\
\text { concreto) }\end{array}$ & 0.45 & 0.20 & 0.23 & 0.20 & 0.24 \\
\hline \multicolumn{2}{|c|}{$\begin{array}{c}\text { Precisión expresada en } \\
\text { términos del coeficiente de } \\
\text { variación } \\
\end{array}$} & $\operatorname{CVr}(\%)$ & $\mathbf{r}(\%)$ & $\operatorname{CVR}(\%)$ & $\mathbf{R}(\%)$ \\
\hline \multicolumn{2}{|c|}{$\mathrm{D}_{\text {nss }}(\mathrm{E}-12) \pm$} & 23.26 & 65.13 & 32.81 & 91.93 \\
\hline \multicolumn{2}{|c|}{$\begin{array}{c}\mathrm{C}_{\mathrm{s}} \% \text { (referido a masa de } \\
\text { concreto) } \pm\end{array}$} & 13.34 & 37.42 & 19.42 & 54.40 \\
\hline \multicolumn{6}{|c|}{$\begin{array}{l}\text { Estos valores están basados en un ejercicio de precisión inter-laboratorios realizado en 2011-2012 [14]. } \\
\text { En el ejercicio han participado } 12 \text { laboratorios y los ensayos se han realizado sobre muestras de concreto } \\
\text { idénticas ( } 2 \text { por ensayo), preparadas de acuerdo a los valores límite expresados en la norma europea EN } \\
206 \text { en lo que se refiere a la composición del concreto, con dos tipos de cemento y dos valores distintos } \\
\text { para la relación agua/cemento (cuatro variables). Los valores de la Tabla son aplicables a los tres } \\
\text { métodos equivalentes de exposición descritos en la norma (inmersión, estanque e inversión). }\end{array}$} \\
\hline
\end{tabular}




\section{ANEJO A \\ (informativo)}

\section{Probeta de ensayo obtenida de un testigo de concreto}

La edad del concreto en la estructura de la cual se van a obtener los testigos debe ser mayor o igual a 28 días de maduración, considerando que un día de maduración es el tiempo requerido para desarrollar una madurez del concreto equivalente a la que obtendría con el curado de un día bajo agua a $20^{\circ} \mathrm{C}$. Tanto la edad como cualquier otra información acerca del curado del elemento, debe ser anotada e incluida en el informe.

El testigo (o testigos) debe ser extraído de acuerdo con los métodos normalizados más relevantes para la investigación, por ejemplo [13]. Cuando el testigo es obtenido de una estructura existente, es esencial que la subprobeta para perfil proceda de una zona que no haya estado expuesta al ingreso de cloruro desde el exterior.

NOTA: Si el propósito del ensayo es determinar las prestaciones de durabilidad de una estructura existente es importante que el concreto ensayado sea obtenido de la zona de recubrimiento del acero de refuerzo. Se sabe que la zona del testigo correspondiente a los 10 mm más externos tiene una mayor concentración de pasta de cemento, hecho que puede influenciar los valores obtenidos para $C_{s}$ y $D_{n s s}$. Por ello frecuentemente dicha zona más externa se corta y descarta, realizando el ensayo sobre la superficie cortada que corresponde a una profundidad de $10 \mathrm{~mm}$ desde la superficie de la estructura. Esta precaución también es aplicable cuando se ensayan probetas moldeadas, tal como se describe en la Figura A.1. Es esencial poder garantizar que en el momento de iniciar el ensayo del recubrimiento de estructuras existentes, la probeta no tenga, ya de partida, un gradiente de contenido de cloruro. Cuando se utilice el procedimiento descrito en esta Recomendación Técnica, cualquier desviación con respecto al método debe ser incluida en el informe.

La Figura A.1 muestra las posiciones relativas de la superficie moldeada, sub-probeta para perfil y sub-probeta para el contenido inicial de cloruro, en el caso de ensayar una probetatestigo para obtener el coeficiente de difusión de cloruro de la zona de recubrimiento de una estructura existente, siempre teniendo en cuenta que no debe existir un gradiente de contenido de cloruro previo al ensayo.

$$
\begin{aligned}
& \text { Clave: } \\
& \text { Superficie moldeada } \\
& \text { Descarte de la rodaja correspondiente a los } 10 \text { mm más externos } \\
& \text { 4 Sub-probeta para perfil de cloruro para el contenido inicial de cloruro } \\
& 5 \text { Testigo restante }
\end{aligned}
$$

Figura A.1. Probeta y sub-probetas para ensayo, obtenidas a partir de un testigo de concreto 


\section{ANEJO B \\ (informativo)}

\section{Montaje y procedimiento típicos para la saturación de concreto a vacío}

\section{B.1 Equipamiento}

La Figura B.1 muestra un montaje típico de equipamiento para la saturación a vacío de probetas de concreto

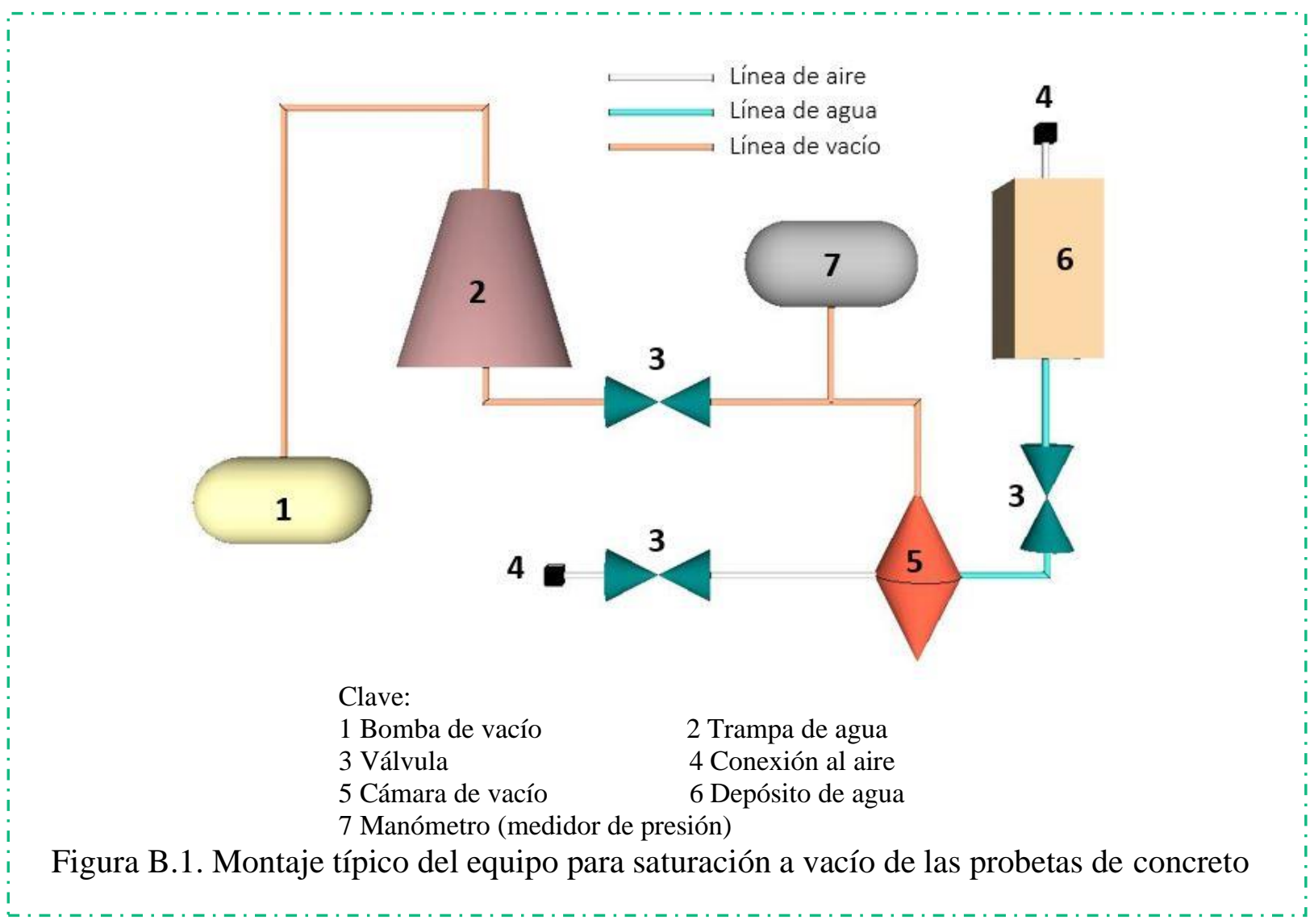

B.1.1 Depósito de agua, contenedor de agua destilada con drenaje en la parte inferior, de capacidad suficiente para cubrir todas las probetas con agua.

B.1.2 Cámara de vacío, de diámetro interno mínimo $250 \mathrm{~mm}$, equipada con tres salidas para conectar el depósito de agua, la bomba de vacío y la atmósfera.

B.1.3 Manómetro, precisión 1 mbar.

B.1.4 Trampa de agua, debe utilizarse para evitar la entrada de agua en la bomba de vacío. Si no se utiliza una trampa de agua, es preciso cambiar el aceite de la bomba después de cada operación.

B.1.5 Bomba de vacío, capaz de reducir la presión a valores entre 10 mbar y 50 mbar.

B.1.6 Tres válvulas y conducciones de fluidos, destinadas a conectar y controlar los flujos de fluidos.

B. 2 Procedimiento

1) Coloque las sub-probetas para perfil en la cámara de vacío y cierre todas las válvulas del contenedor;

2) Abra la válvula de la línea de vacío y ponga en marcha la bomba de vacío para reducir la presión absoluta a un valor en el rango de 10 a 50 mbar (1 a $5 \mathrm{kPa})$, lo que debería conseguirse 
en un tiempo de unos pocos minutos, y mantenga este valor de presión absoluta durante 3 horas;

3) Sin desconectar la bomba de vacío, abra la válvula de la línea de agua durante el tiempo necesario para llenar la cámara de vacío con agua destilada o desmineralizada procedente del depósito de agua. Todas las sub-probetas deberán quedar completamente sumergidas en agua. Durante esta operación debe asegurarse que no entre aire a la cámara de vacío a través de la línea de agua;

4) Mantenga el vacío durante una hora más;

5) Cierre la válvula de la línea de vacío y desconecte la bomba de vacío;

6) Abra la válvula de la línea de aire y permita que la cámara se rellene de aire.

\section{ANEJO C (normativo)}

\section{Método de inmersión para probetas o elementos de concreto grandes}

En este anejo se describe la forma de operar cuando se va a ensayar por inmersión una probeta o elemento de concreto cuyo tamaño es suficientemente grande para poder considerar que la zona de la cual se obtienen las muestras pulverizadas de concreto no se ve afectada por ingreso bidimensional o tridimensional de ión cloruro. Por este motivo no es necesario sellar las superficies de la probeta diferentes a la de exposición. Cuando se utiliza esta técnica, el cociente entre el volumen de la disolución de cloruro y la superficie expuesta de la probeta de concreto, debe cumplir también lo establecido en la sección 5.2.5. La Figura C.1 muestra un ejemplo de esquema adecuado para realizar el ensayo según esta variante.

Cuando se ensaya una probeta sin sellado de las superficies diferentes a la de exposición, la extracción de las muestras pulverizadas de concreto debe realizarse dentro de un área superficial cuya distancia mínima a la arista de la probeta sea de $50 \mathrm{~mm}$, para evitar la influencia de posibles efectos de borde.

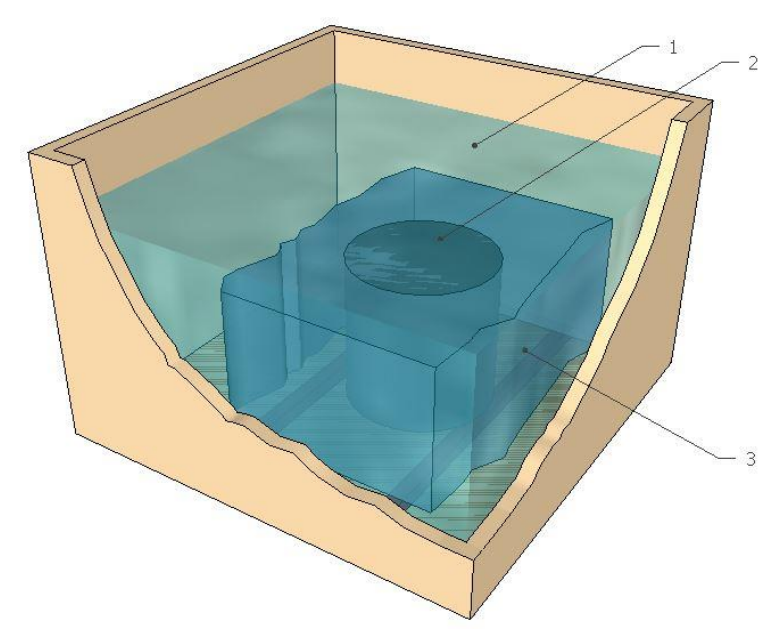

Clave:

1 Disolución de cloruro, de volumen no inferior a $12.5 \mathrm{ml}$ por $\mathrm{cm}^{2}$ de superficie de concreto expuesta

2 Obtención de las muestras de concreto pulverizado en un área superficial cuya distancia mínima a la arista de la probeta sea de $50 \mathrm{~mm}$.

3 Superficies no selladas

Figura C.1. Ejemplo de inmersión de una probeta grande de concreto 


\section{ANEJO D \\ (informativo)}

\section{Recomendaciones y aclaraciones con respecto al método de ensayo}

\section{D.1 Tipos de concretos adecuados para este ensayo}

Los tratamientos superficiales hidrofóbicos, tales como los realizados con silanos, anulan las condiciones para que la difusión iónica pueda tener lugar, ya que evitan que la red de poros se llene de agua y por tanto no permiten la formación de un sistema totalmente interconectado. El ensayo podría utilizarse para determinar la resistencia al cloruro del concreto base, pero no puede utilizarse para determinar la resistencia del concreto tratado con tales productos.

Cuando se esté intentando mejorar la calidad de la superficie de concreto mediante el uso de encofrado de permeabilidad controlada, el procedimiento de ensayo debe modificarse para que la superficie de concreto a ensayar (en contacto con la disolución de cloruro) sea la cara generada por contacto con el encofrado de permeabilidad controlada. En tales casos se precisa tener precaución en la interpretación de resultados ya que dichas probetas, por su naturaleza, presentan en su superficie un gradiente de resistencia al ingreso de cloruro.

Existe poca experiencia en la utilización de este procedimiento para ensayar concretos con fibras, en consecuencia, no es posible garantizar la idoneidad del ensayo para dichos materiales. En el caso de concretos con fibras poliméricas, el contenido de cloruro de las fibras podría hacer que el valor medido en la determinación del contenido inicial de cloruro no fuera válido para todas las capas de la zona del perfil.

\section{D.2 Explicación del uso de agua para el curado y la saturación de las probetas}

Si las probetas fueran curadas en disolución saturada de hidróxido de calcio, esto podría conducir a un recubrimiento de las probetas con partículas de cal y si esas partículas no son retiradas, podría producirse carbonatación en caso de exposición temporal de las probetas al aire, por ejemplo, durante la preparación para el sellado de algunas superficies. Esta capa de carbonato podría afectar a la penetración del cloruro en el concreto.

La saturación a vacío con disolución saturada de hidróxido de calcio conduciría a una entrada de dicho compuesto en la red de poros del concreto, pudiendo por tanto modificarse la estructura de la red de poros y la velocidad de penetración del cloruro, hecho que podría producir errores en la determinación del coeficiente de difusión.

\section{D.3 Recomendaciones para la selección de la disolución de cloruro}

Siempre que sea posible se recomienda utilizar para el ensayo el mismo líquido conteniendo cloruro. Cuando se conozcan las condiciones específicas de exposición y se disponga de muestras de la disolución de cloruro a que van a estar expuestos los elementos o estructura de concreto, debe utilizarse dicho líquido como disolución de cloruro para el ensayo. Debe tenerse en cuenta que no toda el agua de mar es la misma. Si no es posible utilizar el mismo líquido puede prepararse agua de mar artificial a partir de la composición de la disolución de exposición. Si se utilizan diferentes disoluciones de cloruro con la misma concentración de cloruro, por ejemplo agua de mar y una disolución de cloruro de sodio puro, no se obtiene la misma velocidad de ingreso del cloruro en el concreto. Para estructuras de concreto expuestas a sales de deshielo, deben utilizarse disoluciones lo más parecidas posible, en composición y concentración, al líquido de exposición. Cuando no exista o sea desconocida la condición específica de exposición, se recomienda utilizar la disolución de cloruro de sodio de referencia, sección 5.1.2.1. 


\section{D.4 Ajuste de la ecuación solución de la segunda ley de Fick al perfil de cloruro}

El ajuste consiste básicamente en encontrar los valores de los parámetros $C_{\mathrm{s}}$ y $D_{\mathrm{nss}}$, que proporcionan el valor mínimo para la suma de los cuadrados de las diferencias entre los datos medidos experimentalmente y los datos calculados mediante la ecuación solución de la segunda ley de Fick (método de "mínimos cuadrados"). La siguiente función expresa la suma de los cuadrados de las diferencias:

$$
F=\sum_{i}\left(y_{i}-\bar{y}_{i}\right)^{2}
$$

donde $\bar{y}_{i}$ es el contenido de cloruro medido $C\left(x_{i}\right)$ correspondiente a la posición $x_{i}$ (después de sustraer el contenido inicial de cloruro $C_{i}$ ), mientras que $y_{i}$ es el valor correspondiente calculado mediante la ecuación solución de la segunda Ley de Fick (ecuación de la función error):

$$
\begin{aligned}
& \bar{y}_{i}=C\left(x_{i}\right)-C_{\mathrm{i}} \\
& y_{i}=y_{0} \cdot\left[1-\operatorname{erf}\left(\frac{x_{i}}{2 \sqrt{D_{\mathrm{nss}} t}}\right)\right]=y_{0} \cdot \operatorname{erfc}\left(\frac{x_{i}}{2 \sqrt{D_{\mathrm{nss}} t}}\right)
\end{aligned}
$$

donde erf y erfc representan a la función error y al complemento de la función error, respectivamente.

$$
y_{0}=C_{\mathrm{s}}-C_{\mathrm{i}}
$$

En el método normalizado, el contenido de cloruro de la primera muestra obtenida $C\left(x_{1}\right)$ no debe incluirse en el ajuste. En consecuencia, el índice $i$ estará en el rango entre 2 y $n$, siendo $n$ el ordinal correspondiente al "punto cero", véase sección 8. Para conseguir minimizar el valor de la expresión (1), se deben satisfacer las siguientes condiciones:

$$
\begin{aligned}
& \frac{\partial F}{\partial y_{0}}=0 \Rightarrow y_{0}=\frac{\sum_{\mathrm{i}=2}^{n}\left[\bar{y}_{i} \cdot \operatorname{erfc}\left(\frac{x_{i}}{2 \sqrt{D_{\mathrm{nss}} t}}\right)\right]}{\sum_{\mathrm{i}=2}^{n}\left[\operatorname{erfc}\left(\frac{x_{i}}{2 \sqrt{D_{\mathrm{nss}} t}}\right)\right]^{2}} \\
& \frac{\partial F}{\partial D_{\mathrm{nss}}}=0 \Rightarrow y_{0}=\frac{\sum_{\mathrm{i}=2}^{n}\left[\bar{y}_{i} \cdot\left(\frac{x_{i}}{2 \sqrt{D_{\mathrm{nss}} t}}\right) \cdot \exp \left(-\frac{x_{i}^{2}}{4 D_{\mathrm{nss}} t}\right)\right]}{\sum_{\mathrm{i}=2}^{n}\left[\left(\frac{x_{i}}{2 \sqrt{D_{\mathrm{nss}} t}}\right) \cdot \exp \left(-\frac{x_{i}^{2}}{4 D_{\mathrm{nss}} t}\right) \cdot \operatorname{erfo}\left(\frac{x_{i}}{2 \sqrt{D_{\mathrm{nss}} t}}\right)\right]}
\end{aligned}
$$

En consecuencia, la tarea a realizar es seleccionar la pareja más idónea de valores de $y_{0}$ y $D_{\text {nss }}$ para hacer que los valores de las expresiones (5) y (6) sean iguales.

Se puede obtener la pareja más idónea de valores de $y_{0}$ y $D_{\mathrm{nss}}$ mediante una hoja de cálculo, haciendo una matriz que comprenda un rango adecuado de valores de $y_{0}$ y $D_{\text {nss }}$ y ajustar dichos valores hasta minimizar la diferencia entre los valores de las expresiones (5) y (6). Este proceso puede resultar bastante lento y laborioso. Alternativamente se pueden usar programas matemáticos sofisticados, que pueden ser caros. La mejor solución es preparar un programa de ordenador propio que realice la tarea específica. 


\section{BIBLIOGRAFÍA}

1. CEN/TC 51/WG 12, EN 12390-11:2015 (European standard), Testing hardened concrete Part 11: Determination of the chloride resistance of concrete, unidirectional diffusion, April 2014.

2. NT BUILD 443 (Nordic standard), Concrete, Hardened: Accelerated Chloride Penetration, NORDTEST, Espoo, Finland, November 1995.

3. ASTM C 1556-03 (USA standard), Standard test method for determining the apparent chloride diffusion coefficient of cementitious mixtures by bulk diffusion, West Conshohocken, PA, USA, February 2003.

4. Castellote, M.; Andrade, C., Round-Robin Test on methods for determining chloride transport parameters in concrete, (RILEM TC 178-TMC Report), Materials and Structures, 39 (2006) 955-990.

5. Crank, J., The Mathematics of Diffusion, Clarendon, Oxford, UK, 1975, $2^{\text {nd }}$ Edition.

6. Kropp, J.; Hilsdorf, H.K.; Grube, H.; Andrade, C.; Nilsson, L.O., Transport mechanisms and definitions, in: Kropp J., Hilsforf H.K. (Eds.), Performance Criteria for Concrete Durability, E \& FN Spon, London, UK, pp 4-14, 1995.

7. Vennesland, $\varnothing$; Climent, M.A.; Andrade, C., Recommendation of RILEM TC 178-TMC: testing and modeling chloride penetration in concrete. Methods for obtaining dust samples by means of grinding concrete in order to determine the chloride concentration profile, Materials and Structures, 46 (3) (2013) 337-344.

8. Instrucción de Hormigón Estructural (EHE-08), Ministerio de Fomento, Madrid, España, sección 37.3.2, 2008.

9. Castellote, M.; Andrade, C., Round-Robin test on chloride analysis in concrete - Part I: Analysis of total chloride content, Materials and Structures 34 (2001) 532-556.

10. RILEM TC 178-TMC, Recommendation for analysis of total chloride in concrete, Materials and Structures 35 (2002) 583-585.

11. ASTM C 1152 - C 1152 M-04 (USA standard), Standard test method for acid soluble chloride in mortar and concrete, West Conshohocken, PA, USA, 2004.

12. Climent, M.A.; de Vera, G.; Viqueira, E.; López, M.M., Generalization of the possibility of eliminating the filtration step in the determination of acid-soluble chloride content in cement and concrete by potentiometric titration, Cement and Concrete Research. 34 (12) (2004) 22912295.

13. EN 12504-1:2009 (European standard), Testing concrete in structures. Part 1: Cored specimens. Taking, examining and testing in compression, 2009.

14. Validation testing program of CEN/TC 51/(CEN/TC 104)/JWG 12/TG 5 on chloride penetration and carbonation, 2012. 